\title{
Cognitive and personality function in myotonic muscular dystrophy
}

\author{
THOMAS D BIRD, CHRISTINE FOLLET T, ELLEN GRIEP* \\ From the Department of Medicine (Neurology and Medical Genetics), University of Washington School of \\ Medicine, and the Neurology and Psychology Sections of the Veterans Administration Medical Center, Seattle, \\ Washington, USA
}

SUMMARY Twenty-nine patients with myotonic dystrophy from 14 families were tested with the Wechsler and Shipley measures of cognitive function. Forty-one per cent of the subjects had little or no physical handicap. Approximately one-third had low Wechsler scores, whereas $7 \%$ had relatively high scores. There was a trend for affected females to have poorer cognitive function than males. Limited cognitive ability correlated with maternal inheritance of the gene and severe physical handicap, but there were individual exceptions. Strongest cognitive abilities were verbal and informational, whereas the weakest were immediate recall, abstraction and spatial manipulation and orientation. There was no evidence of intellectual decline with time. Signs of cerebral atrophy on CT scans were uncommon, occurring for certain in only one of 19 subjects. Personality profiles were also constructed for 25 myotonic subjects using interview and MMPI techniques. Forty-four per cent of the subjects had unremarkable personality profiles, $24 \%$ had mild personality difficulties and $32 \%$ had prominent personality abnormalities. Serious personality difficulty was most common in patients with low cognitive ability and advanced physical handicap. There was no "typical" personality pattern representative of the entire group. It is likely that many personality problems were the result of individuals with limited resources attempting to cope with their physically deforming and debilitating neuromuscular discrder.

Myotonic muscular dystrophy is an autosomal dominant disorder with high penetrance and tremendously variable expression. In addition to muscle weakness, atrophy and myotonia, the disease also affects hair, gonads, bone, insulin metabolism, eyes, and probably gallbladder, thyroid, and red cell membranes. Mental retardation and personality aberrations have commonly been reported in patients with myotonic dystrophy. However, the frequency, severity and clinical correlates of these cerebral manifestations have never been adequately studied. Harper summarised this state of affairs by noting: "A thorough neuropsychiatric study of

Address for reprint requests: TD Bird, MD, VA Medical Center, Seattle, Washington 98108 , USA.

${ }^{*}$ Deceased.

Received 13 January 1983 and in revised form 15 April 1983. Accepted 7 May 1983

Abstract presented at the 33rd meeting of the American Society of Human Genetics, Detroit, September, 1982. myotonic dystrophy using standardized assessment of intelligence and personality in a representative series of patients seems never to have been performed, surprisingly; such an endeavor might throw valuable light on the likely nature and distribution of the underlying presumed cerebral defects, and is badly needed to supplement the incomplete and largely anecdotal information on which we have to rely at present."

This study was designed to provide some of the missing information alluded to by Harper. We attempted to shed light on the following specific questions: (1) What is the range of intellectual abilities in patients carrying the myotonic dystrophy gene? (2) Does cognitive impairment occur only when the myotonic dystrophy gene is inherited from the mother? (3) Is there a correlation of intellecutal ability with severity of physical handicap? (4) Does cognitive function in this disease deteriorate with time? (5) Are there certain cognitive functions that are more difficult for myotonic dystrophy patients to perform than others? (6) How often do CT brain 
scans show cerebral atrophy in patients with myotonic dystrophy? (7) What proportion of myotonic dystrophy patients have identifiable personality disorders, and are personality problems associated with other variables such as severity of physical handicap, general cognitive function or maternal versus paternal descent of the gene? (8) Is there a "typical personality type" in myotonic dystrophy?

\section{Patients and methods}

Patients were selected from the University of Washington Medical Genetics and Muscular Dystrophy Clinics and the Neurology Clinic at the Seattle Veterans Administration Medical Center. We tested 29 patients from 14 unrelated families affected with classic autosomal dominant myotonic dystrophy. Typical physical characteristics and EMG and slit lamp findings were present in affected persons from each family. ${ }^{1}$ The proband in each family was defined as the index case, that is, the first affected family member to come to medical attention. Ascertainment was probably slightly biased toward more severely affected subjects. Not all family members could be studied because of lack of sufficient funding and geographic distance. Nevertheless, we made a concerted effort to discover and test mildly affected persons. We were successful in this effort because $41 \%$ of the subjects had only mild physical handicap (see below). In ten families all known affected members of a sibship were tested. In three of these all siblings were tested including an unaffected person. In two families we tested affected members in two generations. All but one subject was 15 years of age or older because it is difficult to be certain of the clinical diagnosis in younger persons at risk. One patient with myotonic dystrophy and Down syndrome was included in the longitudinal study of cognitive change and the CT scan evaluation but not in the other comparisons. ${ }^{2}$

Patients were divided into five physical handicap groups. Group I subjects were asymptomatic but discovered to be gene carriers by physical, slit lamp and EMG examinations. Group II subjects had definite but mild symptoms and signs having little or no effect on activities of daily living. Subjects in groups III, IV, V had increasing severity of symptoms, signs and weakness interfering with daily activities. Group V patients were confined to wheelchair. Mental and personality functions were not criteria for physical handicap grouping. Patients were also divided into groups showing maternal or paternal descent of the myotonic dystrophy gene. This was determined by actual examination of parents or by family history and medical records. The affected parent could not be determined for three subjects.

Two tests of cognitive function were employed. The first was the Wechsler Adult Intelligence Scale (WAIS) (Wechsler Intelligence Scale for Children was used in the three adolescent patients). The Wechsler test was chosen because it is widely used, allowed us to compare our results with those of other investigators, allowed us to compare present results with previous tests on our own patients, and provided subtests useful in identifying specific areas of strength and weakness in cognitive function. The second test was the Shipley-Hartford Scale. ${ }^{3}$ This was chosen as a purely verbal measure of intellectual function which eliminates the variable of hand and motor strength that might be compromised in some patients. Twenty subjects were tested with both Wechsler and Shipley measures, eight received Wechsler tests only and one the Shipley only. Differences between group means were evaluated by Student's $t$ test.

Nineteen subjects had unenhanced CT brain scans (EMI-CT1010) including nine of the 11 subjects with low Wechsler scores.

Twenty-five of the myotonic subjects also had personality evaluations. They included 13 males and 12 females ranging from 21 to 73 years (mean $39 \cdot 3$ yrs). They came from 13 families and represented all physical handicap groups I-V. Three siblings with mental retardation were unavailable for personality testing, and the patient with myotonic dystrophy and Down syndrome was not tested. Forty per cent of the subjects came from the least severe physical handicap groups (I-II).

All subjects were interviewed by the senior author and given the Minnesota Multiphasic Personality Inventory (MMPI). The MMPI was chosen because it is a widely used and well-standardised measure of personality traits and characteristics. ${ }^{4}$ The MMPI is a series of 566 true/false questions regarding personal attitudes, beliefs, thoughts and judgments. ${ }^{4}$ Questions and their responses can be grouped into several clinical scales labelled for convenience as hypochondriasis (Hs), depression (D), hysteria (Hy), psychopathic deviate (Pd), masculinity-femininity $(\mathrm{MF})$, paranoia $(\mathrm{Pa})$, psychasthenia $(\mathrm{Pt})$, schizophrenia (Sc), and hypomania (Ma). Other scales include introversion-extroversion $(\mathrm{Si})$, ego strength (Es), low back pain (LBP), social desirability (SD), and dependency (DY). A score above 70 on any scale is considered outside the normal range of responses. The test is not considered a method of making psychiatric diagnoses but rather a means of identifying certain personality characteristics and obtaining a personality profile. Scales $\mathrm{L}, \mathrm{F}$ and $\mathrm{K}$ monitor the validity of responses. High scores on $\mathrm{L}$ and $\mathrm{K}$ suggest denial while elevations on $F$ indicate an unusual number of bizarre responses.

\section{Results}

Table 1 shows the characteristics of the patient population and overall results of cognitive function testing. There were 15 males and 14 females ranging in age from 13 to 73 with a mean of 36.2 years. There was no difference between the ages of the two sexes. Educational background ranged from elementary to graduate school. There were 12 subjects in mild handicap groups (I and II) and 17 persons in the more severely handicapped groups (III through $\mathrm{V}$ ). There were nine instances of maternal descent of the gene and 17 paternal instances (not significant by Chi square test, $p>0 \cdot 1$ ).

The mean Wechsler full scale score for the total group was 90.3 with females having a lower mean 
Table 1 Myotonic dystrophy: population characteristics and cognitive function

\begin{tabular}{|c|c|c|c|}
\hline & Males & Females & Total \\
\hline $\begin{array}{l}\text { Number of subjects } \\
\text { Mean age } \\
\text { Age range } \\
\text { Handicap groups I, II } \\
\text { Handicap groups III, IV, V } \\
\text { Maternal inheritance } \\
\text { Paternal inheritance } \\
\text { Unknown inheritance } \\
\text { Wechsler Full Scale Score (Mean) } \\
\text { (Probands Omitted) } \\
\text { Wechsler Verbal Score (Mean) } \\
\text { Wechsler Performance Score (Mean) } \\
\text { Shipley Verbal Seore (n }=21 \text { ) (Mean) } \\
\text { Shipley Abstract Score (n }=21 \text { ) (Mean) } \\
\text { Patients with Wechsler Full Scale <80 } \\
\text { Patients with Wechsler Full Scale }>120\end{array}$ & $\begin{array}{l}15 \\
39 \cdot 3 \\
13-73 \\
6 \\
9 \\
5 \\
8 \\
2 \\
97 \cdot 7 \\
101 \cdot 3 \\
98 \cdot 6 \\
97 \cdot 3 \\
108 \cdot 2 \\
93 \cdot 2 \\
\mathrm{n}=3(21 \%) \\
\mathrm{n}=2\end{array}$ & $\begin{array}{l}14 \\
32 \cdot 6^{*} \\
15-70 \\
6 \\
8 \\
4 \\
9 \\
1 \\
83 \cdot 0 \dagger \\
90 \cdot 4^{*} \\
87 \cdot 7 \dagger \\
84 \cdot 8 \dagger \\
100 \cdot 0^{*} \\
90 \cdot 1^{*} \\
\mathrm{n}=7(50 \%) \\
\mathrm{n}=0\end{array}$ & $\begin{array}{l}29 \\
36 \cdot 2 \\
13-73 \\
12(41 \%) \\
17(59 \%) \\
9(31 \%) \\
17(59 \%) \\
3(10 \%) \\
90 \cdot 3 \\
96 \cdot 2 \\
91 \cdot 7 \\
90 \cdot 3 \ddagger \\
104 \cdot 3 \\
92 \cdot 78 \\
\mathrm{n}=10(36 \%) \\
\mathrm{n}=2(7 \%)\end{array}$ \\
\hline
\end{tabular}

* Male/Female difference not significant, $p>0.05$.

† Male/Female difference significant, $p<0.05$.

$¥$ Wechsler Verbal/Performance difference not significant, $\mathrm{p}>0.05$.

$\S$ Shipley Verbal/Abstract difference significant, $p<0 \cdot 05$.

score than males ( 83.0 vs. $97 \cdot 7)$. This sex difference was also noted for the Wechsler verbal and performance scores. When probands were excluded the trend for females to have lower Wechsler scores remained but was not statistically significant. Males also tended to score higher on the Shipley test, but the difference between sexes was not significant. There was no significant difference between the mean Wechsler verbal score and the Wechsler performance score for the whole group or within each sex.

Mean Wechsler verbal, performance and full scale scores for the probands were 83.9 $\pm 20.6,85.1 \pm$ 16.5 and $84.9 \pm 19.0$, respectively, and for the nonprobands $97 \cdot 2 \pm 21 \cdot 4,95 \cdot 4 \pm 18 \cdot 3$ and $96 \cdot 2 \pm 20 \cdot 9$ respectively. Although these figures show an obvious trend for probands to have lower Wechsler scores (suggesting some ascertainment bias) none of the differences between these two groups were significant $(p>0 \cdot 1)$.
Figure 1 shows the distribution of Wechsler full scale scores for all subjects. The curve is skewed toward the lower end of the Wechsler scale. Two subjects $(7 \%)$ had scores greater than 120,10 subjects $(36 \%)$ had scores less than 80 . The figure also shows that patients with low Wechsler scores tended to be females with maternal inheritance of the gene. However, there were three males and several instances of paternal inheritance at this lower end of the distribution.

Persons with the myotonic dystrophy gene included a health professional with a four-year graduate degree, an engineering assistant in the aerospace industry and the owner of a private constuction firm. These three persons all had above average Wechsler scores and little or no physical handicap. There was the expected tendency for affected siblings to have similar levels of cognitive ability. Typical of this trend were two sisters and a brother whose Wechsler full scale scores were 72 ,

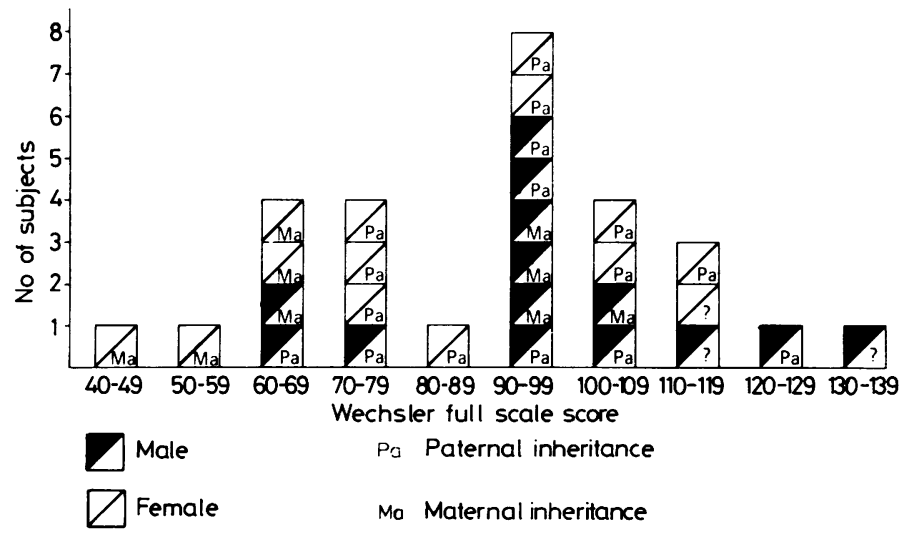

Fig 1 Distribution of Wechsler Full Scale scores for 29 patients with myotonic dystrophy. Each square represents one individual and the symbols within each square indicate sex of the patient and maternal $(\mathrm{Ma})$ or paternal $(\mathrm{Pa})$ inheritance of the myotonic gene. 
75 , and 76 , respectively (paternal inheritance). Two identical twin sisters with maternal inheritance had Wechsler full scale scores of 45 and 51 , and their younger affected brother had a full scale score of 68 . These twins had the lowest Wechsler scores in the study and were the only subjects who had been hypotonic infants. Their brother had a normal infancy. In one sibship with paternal inheritance two affected brothers and an affected sister had full scale scores of 128,106 , and 98 , respectively. This was the greatest variability seen among affected sibs. An asymptomatic but affected father had a full scale score of 134 and his two affected daughters had scores of 117 and 99 . Another affected father had a full scale score of 112 and his affected daughter had a score of 100 .

Financial and geographic constraints precluded the testing of all unaffected family members. However, two affected sisters with maternal inheritance and full scale scores of 61 and 66 had an unaffected sister with a full scale score of 127 . Two affected sibs with full scale scores of 99 and 117 had an unaffected sib who was a university professor. The socio-economic and educational levels of unaffected family members were typical of the general population and not suggestive of poor economic or intellectual performance.

Table 2 shows the results of cognitive function testing in the two inheritance groups. The nine patients with maternal inheritance were slightly younger (not significant), were somewhat more likely to have physical handicap (78\% versus $59 \%$, not significant by Chi square test), and had lower Wechsler scores which were significantly different from the paternal inheritance group on the full and performance scales. Furthermore, although maternal and paternal descent of the gene were equally represented in the 10 subjects with Wechsler full scale scores less than 80 , those with maternal inheritance continued to demonstrate a significantly lower mean Wechsler score. Thus, although evidence of poor cognitive function could be found in some persons with paternal descent of the gene, such limited function was more likely to be found and likely to be of greater severity in persons with maternal inheritance.

Table 3 shows the results of cognitive testing in the handicap groups. Patients from the more severe physical handicap groups tended to be younger, included seven of the nine persons with maternal inheritance and had lower scores on all measures of cognitive function. Note that even when the patients with the lowest Wechsler scores (full scale less than 80 ) were removed from the analysis the patients with more severe physical handicap continued to have lower Wechsler scores.

We also evaluated the mean within subject rankings of the 11 subscales of the Wechsler test. There was a consistent trend for all subjects to perform best on the subscales of similarities, information, vocabulary and picture completion. These subtests primarily require facility with words, word meanings, fund of general information and picture story telling. The patients had most difficulty with the subscales of digit span, object assembly and block design. These subtests primarily require good immediate recall of numbers and facility with spatial orientation of objects and designs. These relative strengths and weaknesses in subscale performance remained the same even when evaluating only the least handicapped subjects or only those with Wechsler full scale scores above 80 . From table 1 it can be seen that on the Shipley test the patients scored higher on the verbal scale compared with the abstract scale. This indicates that verbal abilities are stronger than abilities to find abstract patterns in a sequence of items.

Table 4 shows the longitudinal cognitive function testing that was available on five subjects including the young man with Down syndrome. The interval between tests ranged from 11 to 19 years. There was no instance of decline in cognitive function over this time span. One patient (B) even showed improvement, probably explained by increased motivation, cooperation and education. Only a single individual in the entire study gave any historical indication of

Table 2 Myotonic dystrophy: inheritance groups

\begin{tabular}{|c|c|c|c|}
\hline & Maternal inheritance & Paternal inheritance & $p$ value \\
\hline $\begin{array}{l}\text { Number of subjects } \\
\text { Mean age (yr) } \\
\text { Males/females } \\
\text { Handicap groups III-V } \\
\text { Wechsler Full Scale Score (Mean) } \\
\text { Wechsler Verbal Score (Mean) } \\
\text { Wechsler Performance Score (Mean) } \\
\text { Subjects with Wechsler Full Scale Score }<80 \\
\text { Number of subjects } \\
\text { Handicap groups III-V (n =) } \\
\text { Full Scale Score (Mean) }\end{array}$ & $\begin{array}{l}9 \\
26 \cdot 8 \\
5 / 4 \\
7(78 \%) \\
76 \cdot 3 \\
79 \cdot 0 \\
76 \cdot 1 \\
5(56 \%) \\
4 \\
58 \cdot 2\end{array}$ & $\begin{array}{l}17 \\
35 \cdot 5 \\
8 / 9 \\
10(59 \%) \\
92 \\
93 \cdot 4 \\
92 \cdot 9 \\
5(31 \%) \\
3 \\
73 \cdot 0\end{array}$ & $\begin{array}{l}\text { NS } \\
0.05>p \\
\text { NS } \\
0.025>p\end{array}$ \\
\hline
\end{tabular}


Table 3 Myotonic dystrophy: handicap groups

\begin{tabular}{|c|c|c|c|}
\hline & $\begin{array}{l}\text { Handicap } \\
\text { groups I-II }\end{array}$ & $\begin{array}{l}\text { Handicap } \\
\text { groups III-V }\end{array}$ & p value \\
\hline $\begin{array}{l}\text { Number of subjects } \\
\text { Mean age (yr) } \\
\text { Males/females } \\
\text { Maternal inheritance } \\
\text { Paternal inheritance } \\
\text { Unknown inheritance } \\
\text { Wechsler Full Scale Score (Mean) } \\
\text { Wechsler Verbal Score (Mean) } \\
\text { Wechsler Performance Score (Mean) } \\
\text { Shipley Verbal (Mean) } \\
\text { Shipley Abstract (Mean) } \\
\text { Subjects with Wechsler Full Scale Score }>80 \\
\text { Number of subjects } \\
\text { Full Scale (Mean) } \\
\text { Verbal (Mean) } \\
\text { Performance (Mean) }\end{array}$ & $\begin{array}{l}12 \\
39 \cdot 9 \\
6 / 6 \\
2 \\
7 \\
3 \\
102 \cdot 8 \\
105 \cdot 3 \\
101 \cdot 0 \\
114(\mathrm{n}=9) \\
101(\mathrm{n}=9) \\
9(82 \%) \\
109 \cdot 8 \\
113 \cdot 1 \\
107 \cdot 4\end{array}$ & $\begin{array}{l}17 \\
33 \cdot 3 \\
9 / 8 \\
7 \\
10 \\
0 \\
82 \cdot 2 \\
82 \cdot 9 \\
84 \cdot 0 \\
97(\mathrm{n}=12) \\
84(\mathrm{n}=12) \\
9(53 \%) \\
98 \cdot 3 \\
99 \cdot 1 \\
97 \cdot 4\end{array}$ & $\begin{array}{l}0.01>p \\
0.005>p \\
0.025>p \\
0.01>p \\
0.05>p\end{array}$ \\
\hline
\end{tabular}

intellectual decline and the evidence was limited by emotional depression and a stroke.

Nineteen subjects had unenhanced CT brain scans including nine of the 11 subjects with Wechsler full scale scores less than 80 (Down patient included). Only one scan had signs of moderate ventricular enlargement and mild frontal cortical atrophy. This subject was one of the twins with maternal inheritance of the gene, infantile hypotonia, a handicap grade of III and a Wechsler full scale score of 51 . Three CT scans had evidence of equivocal or borderline cerebral atrophy. One scan indicated a previous left parietal stroke.

Table 5 demonstrates the overall MMPI results of the 25 tested subjects and selected subgroups. Sixty-four per cent of the total group had at least one elevated MMPI scale, and $40 \%$ had three or more elevated scales. There was a slight excess of males over females with elevated MMPI scores. Patients with maternal inheritance of the gene were more apt to have an elevated MMPI scale, but only six instances of maternal descent were studied so the difference was not significant. The patients with more severe physical handicap and patients with low Wechsler full scale scores were much more likely to have elevated MMPI scales. Eighty-seven per cent of the more seriously handicapped patients had elevated scales compared with $30 \%$ for the least handicapped patients (a significant difference), and $100 \%$ versus $47 \%$ for the low and higher Wechsler score groups respectively (not quite significant).

Figure 2 shows the distribution of elevated MMPI scales for the entire group. The three most commonly elevated scales were Sc, Hs and D. The Sc scale contains items characterised by bizarre and unusual thoughts or behaviour. It may reflect social alienation, peculiarities of perception, feelings of persecution, poor family relationships, lack of deep interests, concern with sexual matters and difficulty in concentration and impulse control. The Hs scale is primarily a measure of somatic concern and an index of the importance of bodily functions and symptoms to the subject. The $D$ scale is an index of mood and morale. High scores suggest feeling of uselessness, depression, dejection, discouragement and self-criticism. Several subjects also had elevated $\mathrm{Hy}, \mathrm{Pd}$ or F scales. The Hy scale is closely correlated with the Hs scale and tends to identify persons who attempt to be optimistic and cheerful in the face of difficulties, using denial and rationalisation. The Pd

Table 4 Chronological change in cognitive function

\begin{tabular}{|c|c|c|c|c|c|c|c|}
\hline \multirow[t]{2}{*}{ Subject } & \multirow[t]{2}{*}{ Sex } & \multirow[t]{2}{*}{ Inheritance } & \multirow{2}{*}{$\begin{array}{l}\text { Present } \\
\text { handicap } \\
\text { grade }\end{array}$} & \multicolumn{4}{|c|}{ Age } \\
\hline & & & & \multicolumn{4}{|c|}{ Wechsler Full Scale Score } \\
\hline A & $\mathrm{F}$ & Ma & IV & $\frac{12 \mathrm{yr}}{58}$ & $\frac{19 \mathrm{yr}}{69}$ & $\frac{22 \mathrm{yr}}{66}$ & \\
\hline B & $\mathbf{M}$ & $\mathbf{P a}$ & III & $\frac{13 \mathrm{yr}}{65}$ & $\frac{17 \mathrm{yr}}{78}$ & $\frac{24 \mathrm{yr}}{85}$ & $\frac{31 \mathrm{yr}}{91}$ \\
\hline $\mathrm{C}$ & $\mathbf{M}$ & Ma & $\mathbf{V}$ & $\frac{49 \mathrm{yr}}{98}$ & $\frac{60 \mathrm{yr}}{95}$ & & \\
\hline D & $\mathbf{M}$ & Ma & II & $\frac{12 \mathrm{yr}}{85}$ & $\frac{18 \mathrm{yr}}{89}$ & $\frac{34 \mathrm{yr}}{97^{*}}$ & \\
\hline E & $\begin{array}{l}\text { M (Down } \\
\text { syndrome) }\end{array}$ & $\mathrm{Pa}$ & II & $\frac{5 \mathrm{yr}}{51^{*}+}$ & $\frac{15 \mathrm{yr}}{46}$ & $\frac{21 \mathrm{yr}}{49}$ & \\
\hline
\end{tabular}

* Shipley (WAIS Predicted Score)

†Stanford Binet Test 
Table 5 Myotonic dystrophy: MMPI results of selected subgroups

\begin{tabular}{|c|c|c|c|c|c|c|}
\hline & $n$ & $\begin{array}{l}\text { No elevated } \\
\text { scales }\end{array}$ & $\begin{array}{l}\text { One elevated } \\
\text { scale }\end{array}$ & $\begin{array}{l}\text { Two elevated } \\
\text { scales }\end{array}$ & $\begin{array}{l}\text { Three or more } \\
\text { elevated scales }\end{array}$ & $\begin{array}{l}\text { Total with } \\
\text { elevated scales }\end{array}$ \\
\hline $\begin{array}{l}\text { All subjects } \\
\text { Males } \\
\text { Females } \\
\text { Maternal Inheritance } \\
\text { Paternal Inheritance } \\
\text { Handicap Groups I-II } \\
\text { Handicap Groups III-V } \\
\text { WAIS Full Scale }>80 \\
\text { WAIS Full Scale }<80\end{array}$ & $\begin{array}{r}25 \\
13 \\
12 \\
6 \\
16 \\
10 \\
15 \\
19 \\
6\end{array}$ & $\begin{array}{l}9 \\
4 \\
5 \\
1 \\
5 \\
7 \\
2 \\
9 \\
0\end{array}$ & $\begin{array}{l}5 \\
2 \\
2 \\
2 \\
2 \\
1 \\
3 \\
3 \\
1\end{array}$ & $\begin{array}{l}1 \\
0 \\
1 \\
2 \\
5 \\
1 \\
0 \\
1 \\
0\end{array}$ & $\begin{array}{r}10(40 \%) \\
7 \\
4 \\
1 \\
4 \\
1 \\
10 \\
5 \\
5\end{array}$ & $\begin{array}{r}16(64 \%) \\
9(69 \%) \\
7(58 \%) \\
5(83 \%) * \\
11(69 \%)^{*} \\
3(30 \%) \dagger \\
13(87 \%) \dagger \\
9(47 \%) \ddagger \\
6(100 \%) \ddagger\end{array}$ \\
\hline
\end{tabular}

MMPI = Minnesota Multiphasic Personality Inventory.

WAIS = Wechsler Adult Intelligence Scale.

*Difference not significant, $p>0.05$, Fisher's exact test.

†Difference significant, $p<0.03$, Fisher's exact test.

$\ddagger$ Difference not quite significant, $\mathrm{p}=0.057$, Fisher's exact test.

scale includes items relating to social malajustment and alienation including problems with alcohol, sex, family and the law. The F scale is made up of items rarely answered in the scaled direction by welladjusted persons. A high score may be a sign of poor cooperation or inability to understand the test. Persons with a high score on the F scale have also been found to be rebellious or undergoing severe health problems.

The subjects were classified into three groups by combining results of the clinical interview, the social history and the MMPI. Eleven persons (44\%) were felt to have no personality disorder. They had few, if any, evaluated MMPI scores and demonstrated good judgment and evidence of successfully coping with their social environment including skills with employment, marriage, raising children and managing a home. Six persons $(24 \%)$ had mild personality difficulties that did not interfere with social functioning. Eight subjects (32\%) had prominent personality abnormalities that impaired social relationships. Each member of this latter group had four or more

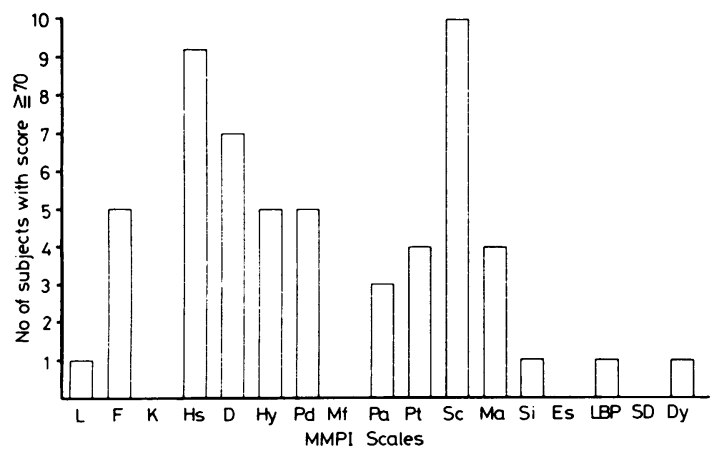

Fig 2 Distribution of elevated MMPI scales (score $\geqslant 70$ ) for 25 myotonic dystrophy patients. See methods and results for definitions of individual scales. elevated MMPI scales (scores above 80 in many instances) and showed major defects of judgment, interpersonal relations and abilities to work and live independently.

Table 6 compares the characteristics of the eight subjects with prominent personality abnormalities with the 11 subjects having no personality change. Those with prominent personality problems tended to be younger, to have more physical handicap and to have lower cognitive abilities. However, note that subject \#12 had considerable physical handicap and a low Wechsler score but no personality dysfunction. Of the eight subjects with serious disorders of personality, two had maternal descent of the gene and six had paternal inheritance. Three major personality characteristics were represented in this group: passive aggressive traits, emotional and social immaturity and depression. Not surprisingly, the three immature subjects (\#2,3 and 8) had the lowest Wechsler scores. (Subjects \#2 and \#3 had difficulty understanding some of the MMPI questions, but also showed evidence of trouble with interpersonal relations and adjusting to new social situations and required sheltered housing.) A patient with severe physical handicap and limited cognitive ability (\#7) was profoundly depressed. The three passive aggressive subjects (\#1,5 and 6) were all males with moderate physical handicap that limited their employment and had low to average cognitive ability. Patients 2 and 3 , and 5 and 8 were two sets of siblings. Patients 2 and 3 had an unaffected sister with no personality dysfunction and a normal MMPI profile. Patients 1, 5, and 8 had other affected siblings without prominent personality dysfunction, and patient 4 had an affected sister and affected father without personality dysfunction. All eight subjects with prominent personality difficulty had obvious myopathic facies and untrained observers would readily identify them as appearing "abnormal" and having physical handicap. Two sub- 
Table 6 Myotonic dystrophy: comparison of subjects with and without prominent personality dysfunction

\begin{tabular}{|c|c|c|c|c|c|c|}
\hline Subject & $\operatorname{Sex}$ & Age (yr) & Handicap group & $\begin{array}{l}\text { WAIS full scale } \\
\text { score }\end{array}$ & $\begin{array}{l}\text { Number with elevated } \\
\text { MMPI scales }\end{array}$ & $\begin{array}{l}\text { Major personality } \\
\text { characteristic }\end{array}$ \\
\hline $\begin{array}{c}\text { Subjects } \\
1 \\
2 \\
3 \\
4 \\
5 \\
6 \\
7 \\
8 \\
\text { Mean }\end{array}$ & $\begin{array}{l}\text { romin } \\
\text { M } \\
\mathrm{F} \\
\mathrm{F} \\
\mathrm{F} \\
\mathrm{M} \\
\mathrm{M} \\
\mathrm{M} \\
\mathrm{F}\end{array}$ & $\begin{array}{l}\text { onality dysfu } \\
43 \\
23 \\
21 \\
30 \\
33 \\
37 \\
51 \\
35 \\
34 \cdot 1^{*}\end{array}$ & $\begin{array}{l}\text { on } \\
\text { III } \\
\text { IV } \\
\text { III } \\
\text { III } \\
\text { III } \\
\text { III } \\
\text { V } \\
\text { II }\end{array}$ & $\begin{array}{l}106 \\
66 \\
61 \\
99 \\
76 \\
97 \\
64 \\
75 \\
80 \cdot 5 \ddagger\end{array}$ & $\begin{array}{l}8 \\
5 \\
4 \\
5 \\
5 \\
4 \\
6 \\
4\end{array}$ & $\begin{array}{l}\text { Passive aggressive } \\
\text { Immature } \\
\text { Immature } \\
\text { Depressed } \\
\text { Passive aggressive } \\
\text { Passive aggressive } \\
\text { Depressed } \\
\text { Immature }\end{array}$ \\
\hline \multicolumn{7}{|c|}{ Subjects without prominent personality dysfunction } \\
\hline $\begin{array}{l}9 \\
10 \\
11 \\
12 \\
13 \\
14 \\
15 \\
16 \\
17 \\
18 \\
19 \\
\text { Mean }\end{array}$ & $\begin{array}{l}\mathbf{M} \\
\mathbf{F} \\
\mathbf{F} \\
\mathbf{F} \\
\mathbf{F} \\
\mathbf{F} \\
\mathbf{F} \\
\mathbf{M} \\
\mathbf{M} \\
\mathbf{F} \\
\mathbf{M}\end{array}$ & $\begin{array}{l}48 \\
51 \\
32 \\
35 \\
34 \\
31 \\
34 \\
31 \\
73 \\
70 \\
58 \\
45 \cdot 2^{*}\end{array}$ & $\begin{array}{l}\text { II } \\
\text { III } \\
\text { II } \\
\text { IV } \\
\text { II } \\
\text { II } \\
\text { II } \\
\text { II } \\
\text { II } \\
\text { II } \\
\text { II }\end{array}$ & $\begin{array}{r}128 \\
98 \\
117 \\
78 \\
88 \\
102 \\
100 \\
97 \\
112 \\
110 \\
134 \\
105 \cdot 8 \dagger\end{array}$ & $\begin{array}{l}0 \\
0 \\
0 \\
0 \\
0 \\
2 \\
1 \\
0 \\
0 \\
0 \\
0\end{array}$ & \\
\hline
\end{tabular}

*Mean ages different, $\mathrm{p}<0 \cdot 05$, Student's $t$ test.

†Mean WAIS Scores Different, p $>0.005$, Student's $t$ test.

jects with low Wechsler scores of 78 and 72 had no prominent personality difficulty.

The MMPI was not administered to the patient with myotonic dystrophy and Down syndrome previously reported from this centre. ${ }^{2}$ However, it is pertinent to note that he was a cooperative and pleasant young man, successfully working in a sheltered workshop with no past history or present indication of personality aberration.

Excessive daytime sleepiness associated with central alveolar hypoventilation has been reported in myotonic dystrophy and could contribute to an appearance of "apathy" or disinterest. ${ }^{5}$ This condition was documented in one of our patients with mild personality problems, and symptoms suggestive of the syndrome were also found in one patient with prominent personality disorder (subject \#8).

\section{Discussion}

Mental retardation associated with myotonic dystrophy has been mentioned on numerous occasions in isolated patients including the early report by Bramwell and Addis. ${ }^{6}$ Maas and Paterson found 17 of 29 patients $(59 \%)$ were "mentally defective." Thomasen found $36 \%$ of his patients to have "reduced intelligence" (not specifically tested), ${ }^{8}$ and Klein reported mental retardation in approximately $21 \%$ of his myotonic dystrophy patients. ${ }^{9}$ All these studies had bias in ascertainment such that severely affected individuals were over-represented. Perceived low intelligence may be confounded by emotional and personality factors as well as education, facial appearance and physical handicap. Thus, the complete range of intellectual abilities in a representative sample of these patients has never been accurately determined nor has the precise frequency of mental retardation. The present study also suffers some ascertainment bias and is not a truly representative sample. However, a determined effort was made to examine mildly affected subjects, and the fact that $41 \%$ of the patients were in the least affected physical handicap groups indicates we were successful in this aim. About one-third of our subjects had Wechsler full scale scores below 80 in close agreement with the findings of Thomasen. ${ }^{8}$ Twenty-nine per cent of our subjects had Wechsler scores at or below 75 which is similar to the prevalence of retardation found by Kline. ${ }^{9}$ In contrast, two of our subjects $(7 \%)$ had Wechsler scores exceeding 120 , demonstrating that the myotonic dystrophy gene is compatible with bright to superior intellect.

The association of mental retardation with the clinical presentation of myotonic dystrophy in infancy has been clearly recognised only in the last two decades. ${ }^{10-13}$ Harper has demonstrated that the majority of myotonic dystrophy patients presenting with hypotonia in infancy also demonstrate mental retardation. ${ }^{1}$ In addition these children nearly always, if not always, have the mother as the 
affected parent. This unusual maternal effect has never been explained. Our study provides further evidence that poor cognitive performance and increasing physical handicap are more likely to be found with maternal descent of the gene. Nevertheless, low Wechsler scores can be found in patients who inherited the myotonic dystrophy gene from the father. Therefore, the low cognitive ability often associated with this gene is at least sometimes unassociated with the intrauterine environment of an affected mother.

Other observers have mentioned a tendency for decreased cognitive function to correlate with increased physical handicap. ${ }^{7}$ We have documented this trend and shown the association to be significant even when patients with excessively low cognitive ability are eliminated from the analysis. This is suggestive evidence that there is a direct effect of the mutant gene on brain function. Nevertheless, there were examples of subjects with mild physical handicap and limited cognitive function and, conversely, patients with normal intellectual ability who had serious physical handicap.

Of additional interest in this study is the difference between sexes found on some tests of cognitive ability. Females had significantly lower Wechsler scores than males. Although this trend continued when probands were omitted from the analysis, it was no longer significant. This would be an important subject for further investigation because previous studies (not specifically testing cognition) have generally found relatively slight or no sex differences in myotonic dystrophy patients. ${ }^{1}$

Decreased cognitive function may also occur in other muscular dystrophies, most often in Duchenne but sometimes in Becker and facioscapulohumeral dystrophies. Verbal abilities have been reported as more impaired than performance functions in these other muscular dystrophies. ${ }^{14-16}$ In one study of Duchenne muscular dystrophy the subjects scored best on the block design and object assembly subtests of the Wechsler, in marked contrast to the results of the present investigation. ${ }^{16}$ In our myotonic patients verbal abilities were best, whereas abilities for immediate recall, abstraction, and spacial orientation of objects were most compromised. This tended to be true regardless of degree of physical handicap or level of cognitive function. This information should be of assistance to employers and vocational training and physical therapy units having to deal with myotonic dystrophy patients.

Refsum reported five of ten patients with myotonic dystrophy demonstrated ventricular enlargement by pneumonencephalography that progressed in some patients over a span of five years. ${ }^{17}$ Harper has reported enlarged cerebral ven- tricles in a single child with myotonic dystrophy by both pneumonencephalography and CT scan. ${ }^{1}$ The neuropathological correlates of the ventricular enlargement and mental retardation in this disease are poorly understood. Reduced brain weight, disordered cortical architecture and neuronal inclusion bodies in the thalamus have been reported..$^{18-20}$ The present study is the first to report CT brain scans in a series of patients with myotonic dystrophy. Evidence of cerebral atrophy was definite in only one subject and possible in three others. We were unable to confirm the findings of Refsum ${ }^{17}$ and the explanation for this discrepancy awaits further study. From CT brain scans there is little evidence for a high frequency of gross cerebral atrophy in myotonic dystrophy.

We were unable to confirm the anecdotal report of Maas and Paterson that intellectual decline over time is common in this disorder. ${ }^{7}$ On the contrary, we could not document such decline for certain in any of our 29 patients, and five persons with chronological Wechsler testing showed no evidence of deterioration over many years. Longitudinal studies of Duchenne muscular dystrophy patients have also shown no decline in cognitive ability. ${ }^{1416}$ This is useful information for physicians and counsellors discussing prognosis of myotonic dystrophy and is also of importance to families, employers and those involved with the education and vocational training of these patients.

The mechanism by which myotonic dystrophy compromises cognitive function remains undetermined. Our study is consistent with the hypothesis that this is an early, stable, direct effect on the brain of a single pleiomorphic gene showing the great variability in expression common to the other manifestations of the disease.

Finally we turn to our findings regarding personality function. Bramwell and Addis, ${ }^{6}$ and Adie and Greenfield $^{21}$ noted many myotonic dystrophy patients were "irritable and quarrelsome," "showed lack of interest," and were often "suspicious and mistrustful." Apathy and lack of initiative were consistently reported by others including Rittmeister, ${ }^{22}$ Stolba, ${ }^{23}$ Thomasen, ${ }^{8}$ and Caughey and Myrianthopoulos. $^{24}$ Maas and Paterson concluded that there was a "characteristic temperament" in this disease that consisted of "morbid cheerfulness, mild grandiosity and lack of drive and initiative."? Ambrosini and Nurnberg concluded that psychopathology is a "primary feature of myotonic dystropy." ${ }^{25}$ Bundey has characterised these individuals as "aggressive and touchy" or "easy-going and feckless." 26 An unattractive stereotype of myotonic dystrophy patients has resulted from these observations. However, most of the information 
regarding behaviour and personality is anecdotal, biased by ascertainment and not standardised. Harper's excellent review of myotonic dystrophy ${ }^{1}$ bears out Caughey's and Myrianthopoulos'24 assessment of mental and personality function in this disorder, but stresses that a detailed study of personality has never been done.

The present study demonstrates that the issue of personality in myotonic dystrophy is more complex than the superficial stereotype often used to describe these patients. We draw attention to the following points from our investigation.

It is clear that a normal personality profile is compatible with the myotonic dystrophy gene. Fortyfour per cent of our subjects fell within the broad range of normal personality functioning. Conversely, some personality disorder is common in myotonic dystrophy. Fifty-six per cent of our patients were judged to have at least mild personality difficulty. The problems were minor in $24 \%$ of the total group, whereas $32 \%$ demonstrated prominent abnormalities. This is not surprising in a group of patients with a chronic debilitating disease that can lead to serious physical handicap and produce a noticeably altered physical appearance. Excessive concern with bodily functions, depression, poor self-image and inadequate social adjustment are understandable reactions of patients attempting to cope with their distressing disorder. Personality characteristics and MMPI profiles similar to those of our myotonic dystrophy patients have been described in patients with other disabling neurologic disorders such as multiple sclerosis. ${ }^{27}$ Leibowitz and Dubowitz found a high rate of emotional disturbance associated with Duchenne muscular dystrophy. ${ }^{16}$ Lynch and colleagues have noted the fear, shame, guilt, denial and withdrawal that may occur in some patients with myotonic dystrophy. ${ }^{28}$

There was a strong tendency for the most prominent personality disorders to occur in patients with the most severe physical and mental disabilities. The combination of advanced physical handicap and limited cognitive function is likely to result in prominent personality disorders and impaired social adjustment. It could be argued that the correlation of personality disorder with impaired cognitive ability indicates that the personality disorder is one facet of a more general cerebral abnormality. The lack of prominent personality difficulties in two patients with low Wechsler scores and prominent personality disorder in three subjects with Wechsler scores in the normal range would argue against this hypothesis, but there is no present way to resolve this issue.

Patients with mild to moderate cognitive deficits may sometimes have difficulty understanding the
MMPI test, but this has not been reported to be a serious problem in the intellectual range represented by our subjects. ${ }^{29}$ Only two of our subjects had some difficulty interpreting the MMPI.

Our results do not support the contention that there is a "typical" personality in myotonic dystrophy. We indeed found examples of passive aggressive and immature personalities, bizarre thoughts and depression. However, these characteristics did not reflect the group as a whole and are more likely to represent attempts at adjusting to difficult and sometimes overwhelming physical, mental and social factors beyond control of the individual.

The findings of our study have important implications for physicians and other health care providers dealing with myotonic dystrophy patients. These professionals must have a clear understanding of the highly variable clinical expression of this disorder, including cognitive and personality function, and should not be swayed by previous stereotypes. This wide range of gene expression should be explained as accurately as possible to the involved families. Physicians and counsellors should attempt to identify myotonic dystrophy patients with personality and cognitive difficulties and guide them to appropriate resources for increasing their opportunities for successfully coping with their frustrations.

Edmund Chaney, $\mathrm{PhD}$, critically reviewed the manuscript. Supported in part by the Gallagher Fund, the Seattle Chapter of the Muscular Dystrophy Association, University of Washington Medical Student research funds, and the Veterans Administration. This manuscript is dedicated to the memory of Ellen Griep who made many valuable contributions to this investigation.

\section{References}

${ }^{1}$ Harper PS. Myotonic Dystrophy. Philadelphia: Saunders, 1979.

${ }^{2}$ Bird TD. Myotonic dystrophy associated with Down Syndrome (trisomy 21). Neurology (NY), 1981;31:440-2.

${ }^{3}$ Paulson MJ, Linn TT. Predicting WAIS IQ from Shipley-Hartford scores. J Clin Psychol Monograph Supplement 29,1970;1-9.

4 Good PKE, Branter JP. A Practical Guide to the MMPI. Minneapolis: Univ. Minn. Press, 1974.

${ }^{5}$ Coccagna G, Mantovani M, Parchi C, Mironi F, Lugaresi E. Alveolar hypoventilation and hypersomnia in myotonic dystrophy. J Neurol Neurosurg Psychiatry 1975;38:977-84.

- Bramwell E, Addis WR. Myotonia Atrophica. Edinburgh Med J 1913;11:21-44.

${ }^{7}$ Maas O, Paterson AS. Mental changes in families affected by dystrophia myotonica. Lancet 1937;1:21-3 
${ }^{8}$ Thomasen E. Myotonia. Denmark: Universitetsforlaget Aarhus, 1948.

${ }^{9}$ Klein D. La dystrophie myotonique (Steinert) et la myotonie congenitale.(Thomsen) en Suisse. J Gen Hum (Suppl) 1958;1:1-328.

${ }^{10}$ Dodge RR, Gamstorp I, Byers R, Russell P. Myotonic dystrophy in infancy and childhood. Pediatrics 1965;35:3-19.

${ }^{11}$ Calderon R. Myotonic dystrophy: A neglected cause of mental retardation. J Pediatr 1966;68:423-31.

12 Watters GV, Williams TW. Early onset myotonic dystrophy. Arch Neurol 1967;17:137-52.

${ }^{13}$ Harper PS. Congenital myotonic dystrophy in Britain. I. Clinical aspects. Arch Dis Child 1975;50:503-13.

${ }^{14}$ Dubowitz V. Involvement of the nervous system in muscular dystrophies in man. Ann NY Acad Sci 1979;317:431-8.

${ }^{15}$ Karagan NJ, Sorensen JP. Intellectual functioning in non-Duchenne muscular dystrophy. Neurology (NY) 1981;31:448-52.

${ }^{16}$ Leibowitz D, Dubowitz V. Intellect and behavior in Duchenne muscular dystrophy. Develop Med Child Neurol 1981;23:557-90.

${ }^{17}$ Refs!ım S, Lonnum A, Sjaastad O, Engeset A. Dystrophia myotonica. Repeated pneumoencephalographic studies in ten patients. Neurology (Minneap), 1967; 17:345-48.

${ }^{18}$ Rosman NP, Kakulas BA. Mental deficiency associated with muscular dystrophy. A neuropathological study. Brain 1966;89:769-87.
${ }^{19}$ Culebras A, Feldman RG, Merk FB. Cytoplasmic inclusion bodies within neurons of the thalamus in myotonic dystrophy. J Neurol Sci 1973;19:319-29.

${ }^{20}$ Wisniewski HM, Berry K, Spiro AJ. Ultrastructure of thalamic neuronal inclusions in myotonic dystrophy. $J$ Neurol Sci 1975;24:321-9.

${ }^{21}$ Adie WJ, Greenfield JG. Dystrophia Myotonica (myotonia atrophica). Brain 1923;46:73-127.

${ }^{22}$ Rittmeister JF. Psychische befunde bei einem geschlecgt mit myotoner dystrophie. Schweiz Arch Neurol Psych 1939;43:329-59.

${ }^{23}$ Stolba R. Psychisches stammhirnsyndrom bei dystrophia myotonica. Confin Neurol 1948;8:185-211.

${ }^{24}$ Caughey JE, Myrianthopoulos NC. Dystrophia Myotonica and Related Disorders. Springfield: Charles C. Thomas, 1963.

${ }^{25}$ Ambrosini P, Nurnberg HG. Psychopathology? A primary feature of myotonic dystrophy. Psychosomatics 1979;20:393-9.

${ }^{26}$ Bundey S. Clinical evidence for heterogeneity in myotonic dystrophy. J Med Genet 1982;19:341-8.

${ }^{27}$ Peyser J, Edwards K, Poser C. Psychological profiles in patients with multiple sclerosis. Arch Neurol 1980;37:437-40.

${ }^{28}$ Lynch HT, Tips RL, Krush A. Psychodynamics in a chronic debilitating hereditary disease (myotonia dystrophica). Arch Gen Psychiat 1966;14:153-7.

${ }^{29}$ Lacks PB, Keefe K. Relationships among education, the MMPI and WAIS measures of psychopathology. $J$ Clin Psychol 1970;26:468-70.

\begin{abstract}
Addendum
"Since acceptance of this manuscript two additional pertinent references have been found. They are:

Billings EG, Ravin A. A Psychiatric Study of Patients Manifesting Dystrophia Myotonica. Am J Psychiatry 1941;97: 1116-34.

Woodward JB, Heaton RK, Simon DB, Ringel SP. Neuropsycholgical Findings in Myotonic Dystrophy. J Clin Neuropsychol 1982;4:335-42."
\end{abstract}

